\title{
Ankle-Brachial Index as a Predictor for Cardiovascular Disease in Postmenopausal Women
}

\author{
Lakshmi Lasya Manchikanti ${ }^{1}$ \\ Madhuri Taranikanti² \\ Rohith Kumar Guntuka² \\ ${ }^{1}$ ESIC Medical College, Hyderabad, Telangana, India \\ 2Department of Physiology, ESIC Medical College, Sanathnagar, \\ Hyderabad, Telangana, India \\ ${ }^{3}$ Department of Community Medicine, ESIC Medical College, \\ Sanathnagar, Hyderabad, India \\ Ind J Car Dis Wom 2019;4:15-19
}

Akhila Dronamraju² Sudha Bala ${ }^{3}$

\begin{abstract}
Address for correspondence Lakshmi Lasya Manchikanti, II MBBS student, ESIC Medical College, Hyderabad 500038, Telangana, India (e-mail:lasyamanchikanti@gmail.com).
\end{abstract}

\section{Abstract}

\section{Keywords}

- ankle-brachial index

- peripheral artery disease

- cardiovascular disease

- menopause
Background and Aim Menopausal women are at an increasing risk of cardiovascular diseases due to ovarian failure with estrogen deficiency. Redistribution of fat leading to abdominal obesity is a risk factor for cardiovascular disease. Dyslipidemia is one of the risk factors for peripheral artery disease (PAD) and coronary artery disease (CAD). Prevalence of PAD in women is similar or even higher than men, especially after menopause. ankle-brachial index (ABI) is a gold standard technique to diagnose PAD and acts as an independent prognostic marker to identify patients with high cardiovascular risk. This study aims to compare the $A B I$ between pre- and postmenopausal women and to show that routine use of $A B I$ as a screening tool can be valuable in predicting mortality and morbidity from heart diseases in peri- and postmenopausal women.

Material and Methods A cross-sectional study was done on a total of 107 women with no prior medical diseases such as hypertension, diabetes mellitus, cardiovascular diseases, and history of smoking. Fifty pre- and 57 postmenopausal women were included in this study. Anthropometric parameters such as height, weight, and body mass index (BMI) were measured. $\mathrm{ABI}$ was calculated by measuring the systolic pressures at posterior tibial artery and brachial artery, as per the protocols using digital data acquisition system.

Results BMI in postmenopausal women was significantly higher with $p=0.0023$. Systolic and diastolic blood pressures were significantly higher in postmenopausal women ( $p=0.000001)$, and ABI was found to be significantly lower in postmenopausal women particularly on the left side.

Conclusion $\mathrm{ABI}$ serves as an efficient indicator of PAD. It becomes necessary to understand the progression of PAD as its presence can increase the risk of mortality and morbidity from CAD. Early diagnosis of cardiovascular disease through simple techniques such as $A B I$ measurement would provide scope for early interventional strategies.

\section{Introduction}

Cardiovascular diseases are on the rise even in developing countries such as India. ${ }^{1,2}$ In general, premenopausal women are spared probably due to the cardioprotective role of estrogen. ${ }^{3-5}$ However, women who have attained menopause are at an increasing risk of cardiovascular disease due to factors such as ovarian failure and redistribution of fat leading to estrogen deficiency and abdominal obesity respectively, both of which are risk factors for cardiovascular disease. ${ }^{6}$ Studies on lipid profile in postmenopausal women have shown alterations in lipid levels within 1 year of the last menstrual period independent of age. ${ }^{7}$ Previous studies have also shown that menopausal transition is associated with loss or reduction in the protective effects of high-density lipoprotein 
(HDL) cholesterol. ${ }^{8}$ Dyslipidemia is one of the established risk factors for peripheral artery disease (PAD) as well as coronary artery disease (CAD). ${ }^{9}$ PAD serves as an effective marker of atherosclerosis, and such patients, in general, have an increased risk of myocardial infarction, stroke, and even death. ${ }^{10}$ Though historically PAD was seen in men, recent data suggest that the prevalence of PAD in women is similar or even higher than men, ${ }^{11-14}$ especially after menopause. It increases the risk of mortality and morbidity from CAD. ${ }^{15}$ Measurement of ankle-brachial index (ABI) is considered a gold standard technique to diagnose PAD. ABI measurement is a simple, noninvasive test that is a sensitive and cost-effective tool and is valuable for screening of PAD. ABI is used as an independent prognostic marker to identify patients with high cardiovascular risk. ${ }^{16-21}$ However, very few studies are done so far particularly in India to show that ABI measurement could be used as an effective screening tool to assess cardiovascular risk in postmenopausal women. Hence, this study was taken up with the following objectives:

1. To compare the ABI between pre- and postmenopausal women.

2. To show that routine use of $A B I$ as a screening tool can be valuable in predicting mortality and morbidity from heart diseases in peri- and postmenopausal women.

\section{Material and Methods}

A cross-sectional study was done on a total of 107 women with no prior medical diseases such as hypertension, diabetes mellitus, cardiovascular diseases, and history of smoking. Fifty women aged between 15 and 45 years included in group I, who were in the premenopausal period and were taken as controls, and 57 women aged $>45$ years were included in group II, who were in the postmenopausal period and served as cases. Menopause is defined as women with absence of menstrual period for 12 consecutive months. A careful history was taken to exclude women with any systemic disease, and clinical examination was done to exclude hypertension. The data were entered into a data collection format prepared for the study. Blood pressure (BP) of patients was measured in the supine position after resting for 5 minutes and three digital readings were taken with Lab Chart Pro 8.0 (ADInstruments Pty Limited). ABI was measured using Lab Chart Pro 8.0 in the Department of Physiology. ABI was measured by taking the ratio of maximum systolic pressure at the ankle by the maximum systolic pressure at the arm for which systolic blood pressure (SBP) from both brachial arteries and posterior tibial arteries of both the lower limbs was measured after the patient rested in the supine position for at least 10 minutes. It is found to be a specific and sensitive marker for PAD. An informed consent was taken from all the participants of the study and the institute's ethics committee permission was obtained.

\section{Measurement Protocol}

\section{Anthropometry}

1. Height was measured to the nearest centimeter using a stadiometer.
2. Weight was measured using a digital scale in kilogram.

3. BMI was calculated using the formula weight/height ${ }^{2}$ $\left(\mathrm{kg} / \mathrm{m}^{2}\right)$. BMI $<25$ was considered normal or nonobese and $>25$ was considered being overweight or obese.

The guidelines given by the American Heart Association were followed while measuring ABI. The patient was made to rest in the supine position for 10 minutes with the head and heels supported at a comfortable room temperature. Patients were instructed to remain still during the measurement.

The ABI kit was designed and standardized by proper calibration. Two cuffs were connected to a single pressure transducer to measure the ankle and brachial pressures simultaneously with single inflation of the cuff that was connected to the PowerLab system, Lab Chart Pro 8.

\section{Measurement of brachial artery pressure-BP cuff} placement: The patient is kept in supine position for 10 minutes. BP cuff is tied on the upper arm just above the cubital fossa with the limb at the level of the heart. The phonocardiogram transducer is placed in the cubital fossa over the brachial pulse and is connected to PowerLab system.

\section{Measurement of ankle pressures-BP cuff placement:} The patient is kept in supine position for 10 minutes. BP cuff is tied $2 \mathrm{~cm}$ above the superior aspect of medial malleolus. The phonocardiogram transducer is placed over the posterior tibial artery in the foot and is connected to PowerLab system.

Calibration of the instrument was done to maintain accuracy. Both the BP cuffs of upper and lower limbs were progressively inflated simultaneously to $20 \mathrm{~mm} \mathrm{Hg}$ above the SBP using pressure transducer (ABI kit) of the PowerLab system 8/35. Then the cuffs were slowly deflated. The BP channel setup in the lab chart software shows the rise and fall of pressure waves, and the phonocardiogram channel shows the Korotkoff sound recordings reflecting the systolic and diastolic pressures. BP was noted from the waveforms on the lab chart software recordings with comments placed at appropriate places, and the data were exported onto the Excel sheet provided with the software. The procedure is repeated in the opposite limbs. The same sequence of measurements was used for all patients.

The values were entered in the Excel sheet provided with the software of the PowerLab system.

3. Measurement of BP: Of the three recordings from left upper limb, the first reading was ignored and the average of the second and third readings was considered as the mean SBP and diastolic blood pressure (DBP) of each patient. The pulse pressure and mean arterial pressure were then calculated. The values were recorded up to two decimal places.

4. Calculating ABI: The ABI was calculated for each set of limbs. ABI value was determined by taking the highest pressure in the posterior tibial artery, divided by higher of the two brachial systolic pressures (between the second and third readings) from each upper limb. ${ }^{22}$ The ABI values were recorded up to two decimal places. The lower of the two values was taken as the final ABI result for the patient. 


\section{Interpretation}

The normal cutoff values for ABI, adopted by most studies, are between 0.9 and 1.4. Pressure in the ankle is normally higher than the arm. $\mathrm{ABI}<0.9$ is considered an independent and powerful marker of cardiovascular risk and is diagnostic of PAD. ${ }^{23-25}$ Further, PAD was graded as mild to moderate if $\mathrm{ABI}$ was between 0.4 and 0.9 , and severe if $\mathrm{ABI}$ was $<0.4 .^{21}$

\section{Observations and Results}

Total 107 women were included in this study, of whom the number of premenopausal women was 50 and that of postmenopausal women was 57. The mean age of premenopausal women included in this study was 25.4 years and that of postmenopausal women was 54.53 years. A comparison of anthropometric data of pre- and postmenopausal women has shown the mean BMI to be significantly higher in postmenopausal women with $p=0.0023$ (-Table 1). When the BP was measured in the right and left upper limbs, it was found that SBP, DBP, pulse pressure, and mean arterial pressure were significantly higher $(p=0.00001)$ in postmenopausal women (-Table 2). When the ABIs of the two groups were compared, it was found that there was a significant fall in left $A B I$ in postmenopausal women whereas the right $\mathrm{ABI}$ did not show any significant difference (-Table 3 ). Postmenopausal women were further stratified based on grading of ABI into normal, definite PAD, and high ABI. Out of the 57 postmenopausal women, 54 women had normal right $\mathrm{ABI}(0.9-1.4)$ whereas 52 had normal left $\mathrm{ABI}$ values. When measurements of $\mathrm{ABI}$ were done on the left side, it was seen that three women had $\mathrm{ABI}<0.9$ indicating a definite $\mathrm{PAD}$ and two had $\mathrm{ABI}>1.4$

Table 1 Anthropometric data of the study participants

\begin{tabular}{|l|l|l|}
\hline Parameters & $\begin{array}{l}\text { Premenopausal } \\
\text { women }\end{array}$ & $\begin{array}{l}\text { Postmenopausal } \\
\text { women }\end{array}$ \\
\hline Mean age $(\mathrm{y})$ & $25.4 \pm 9.84$ & $54.53 \pm 7.84$ \\
\hline Mean height $(\mathrm{cm})$ & $156.76 \pm 6.18$ & $151.79 \pm 6.9$ \\
\hline Mean weight $(\mathrm{kg})$ & $58.5 \pm 9.52$ & $61.28 \pm 13.6$ \\
\hline BMI $\left(\mathrm{kg} / \mathrm{m}^{2}\right)$ & $23.78 \pm 3.99$ & $26.89 \pm 5.96$ \\
\hline
\end{tabular}

Abbreviation: BMI, body mass index.
Table 3 Comparison of ABI Index between pre- and postmenopausal women

\begin{tabular}{|l|l|l|l|}
\hline $\mathrm{ABI}$ & $\begin{array}{l}\text { Premenopausal } \\
\text { women }\end{array}$ & $\begin{array}{l}\text { Postmenopausal } \\
\text { women }\end{array}$ & $p$ Value \\
\hline Right & $1.09 \pm 0.11$ & $1.05 \pm 0.12$ & $\begin{array}{l}0.113 \text { (not } \\
\text { significant) }\end{array}$ \\
\hline Left & $1.16 \pm 0.16$ & $1.08 \pm 0.13$ & $\begin{array}{l}0.0049 \\
\text { (significant) }\end{array}$ \\
\hline
\end{tabular}

Abbreviation: $\mathrm{ABI}$, ankle-brachial index.

Table 4 Grading of $\mathrm{ABI}$ values in postmenopausal women

\begin{tabular}{|l|l|l|l|}
\hline Parameter & $\begin{array}{l}\text { Normal ABI } \\
\mathbf{0 . 9 - 1 . 4}\end{array}$ & $\begin{array}{l}\text { Definite PAD } \\
<0.9\end{array}$ & $\begin{array}{l}\text { High ABI } \\
>1.4\end{array}$ \\
\hline Right ABI N & 54 & 2 & 1 \\
\hline Left ABI N & 52 & 3 & 2 \\
\hline
\end{tabular}

Abbreviations: $\mathrm{ABI}$, ankle-brachial index; $\mathrm{PAD}$, peripheral artery disease.

indicating risk of future cardiovascular events. On the right side, two women had ABI values $<0.9$ and only one had ABI $>1.4$ ( - Table 4). When the postmenopausal women with normal $\mathrm{ABI}$ between 0.9 and 1.4 were further stratified into low normal $(1$ to $<1.1)$ and borderline $A B I(0.9$ to $<1)$, it was found that $38.9 \%$ had low normal right $\mathrm{ABI}, 40.38 \%$ had low normal left $\mathrm{ABI}$, and $31.48 \%$ had right borderline ABI whereas $25 \%$ had left borderline ABI (-Table $\mathbf{5}$ ). This stratification has shown that $31.48 \%$ of women had higher risk of PAD on the right side as against $25 \%$ on the left side. It was also seen that 38.9 to $40.38 \%$ of women had low normal ABI. Both these groups have higher chances of progressing to PAD. When BMI and $\mathrm{ABI}$ values were correlated, it was found to be technically positive for left $\mathrm{ABI}$ and negative for right $\mathrm{ABI}$, but the correlation was weak ( $r=0.0073$ for left $\mathrm{ABI}$ and $r=-0.0892$ for right $A B I)$. Pearson's correlation coefficient was calculated to look for any correlation between $\mathrm{ABI}$ and duration of menopause. No significant correlation was observed ( - Table 6 ).

\section{Discussion}

This study was taken up with the objective of assessing and comparing $\mathrm{ABI}$, which is a marker of PAD, between pre- and

Table 2 Blood pressure measurements in right and left upper limbs

\begin{tabular}{|l|l|l|l|}
\hline Mean brachial blood pressure $(\mathrm{mm} \mathrm{Hg})$ & Premenopausal women $(n=50)$ & Postmenopausal women $(n=57)$ & $p$ Value \\
\hline Right & $119.28 \pm 14.18$ & $141.04 \pm 25$ & 0.00001 \\
\hline Systolic & $63.66 \pm 12.9$ & $69.76 \pm 13.5$ & 0.00001 \\
\hline Diastolic & $55.62 \pm 17.33$ & $71.28 \pm 21.33$ & 0.00001 \\
\hline Pulse pressure & $82.2 \pm 10.6$ & $93.52 \pm 15.12$ & 0.00001 \\
\hline Mean arterial pressure & \multicolumn{3}{|l|}{} \\
\hline Left & $110.46 \pm 14.53$ & $138.84 \pm 24.97$ & 0.00001 \\
\hline Systolic & $59.51 \pm 5.96$ & $70.03 \pm 12.65$ & 0.00001 \\
\hline Diastolic & $51.21 \pm 13.73$ & $68.82 \pm 23.01$ & 0.00001 \\
\hline Pulse pressure & $74.67 \pm 7.22$ & $92.97 \pm 14.03$ & 0.00001 \\
\hline Mean arterial pressure & &
\end{tabular}


Table 5 Grading ABI into low and borderline subjects among postmenopausal women

\begin{tabular}{|l|l|l|}
\hline Parameter & $\begin{array}{l}\text { Low normal } \mathrm{ABI} \\
1 \text { to }<1.1\end{array}$ & $\begin{array}{l}\text { Borderline } \mathrm{ABI} \\
0.9 \text { to }<1.0\end{array}$ \\
\hline Right $\mathrm{ABI}$ & $21(38.9 \%)$ & $17(31.48 \%)$ \\
\hline Left $\mathrm{ABI}$ & $21(40.38 \%)$ & $13(25 \%)$ \\
\hline
\end{tabular}

Abbreviation: $\mathrm{ABI}$, ankle-brachial index.

Table 6 Correlation of $A B I$ with duration of menopause

\begin{tabular}{|l|l|l|l|}
\hline $\begin{array}{l}\text { Duration of } \\
\text { menopause }(y)\end{array}$ & Left ABI & Right ABI & $\begin{array}{l}\text { Lower of the } \\
\text { two ABI }\end{array}$ \\
\hline $0-5$ & 1.07 & 1.03 & 1.03 \\
\hline $6-10$ & 1.08 & 1.07 & 1.07 \\
\hline $11-15$ & 1.05 & 1.07 & 1.05 \\
\hline$>15$ & 1.08 & 1.06 & 1.06 \\
\hline
\end{tabular}

Abbreviation: $\mathrm{ABI}$, ankle-brachial index.

Note: Correlation coefficient $r=-0.1327$ for left $A B I$ and $r=0.0687$ for right $A B I$. No significant correlation between duration of menopause and $A B I$ values was observed.

postmenopausal women. It is necessary to understand the progression of PAD as its presence increases the risk of mortality and morbidity from CAD in patients by almost sixfold. ${ }^{15}$ ABI serves as an efficient indicator of PAD. Risk factors for PAD and CAD are comparable including dyslipidemia and obesity. ${ }^{9}$ Our study has shown a weak positive correlation between BMI and ABI, which is consistent with other studies. ${ }^{26}$ Our study has also shown the SBP and DBP to be higher in postmenopausal women, which is similar to studies done previously. ${ }^{27}$ Menopause accelerates the progression of atherosclerosis leading to arterial stiffness and high BPs. Estrogen deficiency in menopause is thought to augment the age-related arterial stiffness. ${ }^{28} \mathrm{ABI}$ that is used to detect PAD was found to be significantly lower in postmenopausal women in our study. This finding would help make early interventions to prevent deaths due to CAD or stroke in these women. PAD is associated with increased levels of inflammation, thrombosis, and coagulation. Postmenopausal women have elevated levels of endothelin and androgens that further increase endothelin levels. However, the mechanism by which endothelin increases remains unclear. ${ }^{29}$ High endothelin levels possibly contribute to oxidative stress with reduction in $\mathrm{NO}$ and loss of vasodilator effects causing high BPs and narrowing of vessels leading to peripheral arterial disease. This effect is accelerated and augmented in postmenopausal women. ${ }^{30-32}$ Normal ABI levels in premenopausal women are attributed to higher levels of nitric oxide and estrogens providing cardioprotective effects.

\section{Conclusion}

This study would serve as a means to show that a noninvasive and reproducible technique may be used routinely as a screening tool to assess cardiovascular health of postmenopausal women. The prevalence of obesity is generally higher in women than men and more so during the postmenopausal period. Such women need special attention as they are at a higher risk for cardiovascular diseases when compared with nonobese women. ABI can be used as an efficient screening tool for diagnosis of PAD that may be associated with adverse cardiovascular events. Hence, ABI measurement would provide clues for early interventional strategies so as to delay the onset of cardiovascular diseases to improve the quality of life in such women.

\section{Funding}

Prajwalika Scholarship Programme (2018) of WINCARS association for students.

\section{Conflicts of Interests}

None.

\section{Acknowledgment}

We thank the study participants for their cooperation during this study.

\section{References}

1 Reddy KS, Yusuf S. Emerging epidemic of cardiovascular disease in developing countries. Circulation 1998;97(6):596-601

2 Celermajer DS, Chow CK, Marijon E, Anstey NM, Woo KS. Cardiovascular disease in the developing world: prevalences, patterns, and the potential of early disease detection. J Am Coll Cardiol 2012;60(14):1207-1216

3 Skafar Debra F, Xu R, Morales J, Ram J, Sowers JR. Female sex hormones and cardiovascular disease in women. J Clin Endocrinol Metab 1997;82(12):3913-3918

4 Campos H, Walsh BW, Judge H, Sacks FM. Effect of estrogen on very low density lipoprotein and low density lipoprotein subclass metabolism in postmenopausal women. J Clin Endocrinol Metab 1997;82(12):3955-3963

5 Mendelsohn ME, Karas RH. The protective effects of estrogen on the cardiovascular system. N Engl J Med 1999;340(23):1801-1811

6 Misra A, Khurana L. The metabolic syndrome in South Asians: epidemiology, clinical correlates and possible solutions. International Diabetes Monitor 2009;21:92-101

7 Matthews KA, Crawford SL, Chae CU, et al. Are changes in cardiovascular disease risk factors in midlife women due to chronological aging or to the menopausal transition? J Am Coll Cardiol 2009;54(25):2366-2373

8 Woodard GA, Brooks MM, Barinas-Mitchell E, Mackey RH, Matthews KA, Sutton-Tyrrell K. Lipids, menopause, and early atherosclerosis in Study of Women's Health Across the Nation Heart women. Menopause 2011;18(4):376-384

9 Lloyd-Jones D, Adams R, Carnethon M, et al; American Heart Association Statistics Committee and Stroke Statistics Subcommittee. Heart disease and stroke statistics-2009 update: a report from the American Heart Association Statistics Committee and Stroke Statistics Subcommittee. Circulation 2009;119(3):e21-e181

10 Vogt MT, Cauley JA, Kuller LH, Nevitt MC. Functional status and mobility among elderly women with lower extremity arterial disease: the Study of Osteoporotic Fractures. J Am Geriatr Soc 1994;42(9):923-929

11 Sigvant B, Wiberg-Hedman K, Bergqvist D, et al. A population-based study of peripheral arterial disease prevalence with special focus on critical limb ischemia and sex differences. J Vasc Surg 2007;45(6):1185-1191

12 Diehm C, Schuster A, Allenberg JR, et al. High prevalence of peripheral arterial disease and co-morbidity in 6880 
primary care patients: cross-sectional study. Atherosclerosis 2004;172(1):95-105

13 Moussa ID, Jaff MR, Mehran R, et al. Prevalence and prediction of previously unrecognized peripheral arterial disease in patients with coronary artery disease: the Peripheral Arterial Disease in Interventional Patients Study. Catheter Cardiovasc Interv 2009;73(6):719-724

14 He Y, Jiang Y, Wang J, Fan L, Li X, Hu FB. Prevalence of peripheral arterial disease and its association with smoking in a population-based study in Beijing, China. J Vasc Surg 2006;44(2):333-338

15 Hirsch AT, Criqui MH, Treat-Jacobson D, et al. Peripheral arterial disease detection, awareness, and treatment in primary care. JAMA 2001;286(11):1317-1324

16 Murabito JM, Evans JC, Larson MG, Nieto K, Levy D, Wilson PWF; Framingham Study. The ankle-brachial index in the elderly and risk of stroke, coronary disease, and death: the Framingham Study. Arch Intern Med 2003;163(16):1939-1942

17 Resnick HE, Lindsay RS, McDermott MM, et al. Relationship of high and low ankle brachial index to all-cause and cardiovascular disease mortality: the Strong Heart Study. Circulation 2004;109(6):733-739

18 Lee AJ, Price JF, Russell MJ, Smith FB, van Wijk MCW, Fowkes FGR. Improved prediction of fatal myocardial infarction using the ankle brachial index in addition to conventional risk factors: the Edinburgh Artery Study. Circulation 2004;110(19):3075-3080

19 Koji Y, Tomiyama H, Ichihashi $\mathrm{H}$, et al. Comparison of anklebrachial pressure index and pulse wave velocity as markers of the presence of coronary disease in subjects with high risk of atherosclerotic disease. Am J Cardiol 2004;94:868-872

20 Lange S, Trampisch HJ, Haberl R, et al. Excess 1-year cardiovascular risk in elderly primary care patients with a low ankle-brachial index (ABI) and high homocysteine level. Atherosclerosis 2005;178(2):351-357

21 McDermott MM, Liu K, Criqui MH, et al; The Multi-Ethnic Study of Atherosclerosis. Ankle-brachial index and subclinical cardiac and carotid disease: the multi-ethnic study of atherosclerosis. Am J Epidemiol 2005;162(1):33-41

22 Hirsch AT, Haskal ZJ, Hertzer NR, et al. ACC/AHA 2005 Guidelines for the Management of Patients With Peripheral Arterial Disease (Lower Extremity, Renal, Mesenteric, and Abdominal
Aortic): a collaborative report from the American Association for Vascular Surgery/Society for Vascular Surgery, Society for Cardiovascular Angiography and Interventions, Society for Vascular Medicine and Biology, Society of Interventional Radiology, and the ACC/AHA Task Force on Practice Guidelines (Writing Committee to Develop Guidelines for the Management of Patients With Peripheral Arterial Disease) J Am Coll Cardiol 2006;47:e1-e192

23 Greenland P, Abrams J, Aurigemma GP, et al. Prevention Conference $\mathrm{V}$ : beyond secondary prevention: identifying the high-risk patient for primary prevention: noninvasive tests of atherosclerotic burden: Writing Group III. Circulation 2000;101(1):E16-E22

24 Weitz JI, Byrne J, Clagett GP, et al. Diagnosis and treatment of chronic arterial insufficiency of the lower extremities: a critical review. Circulation 1996;94(11):3026-3049

25 Hiatt WR. Medical treatment of peripheral arterial disease and claudication. N Engl J Med 2001;344(21):1608-1621

26 Lu B, Zhou J, Waring ME, Parker DR, Eaton CB. Abdominal obesity and peripheral vascular disease in men and women: a comparison of waist-to-thigh ratio and waist circumference as measures of abdominal obesity. Atherosclerosis 2010;208(1):253-257

27 Abbas SZ, Sangawan V, Das A, Pandey AK. Assessment of cardiovascular risk in natural and surgical menopause. Indian J Endocrinol Metab 2018;22(2):223-228

28 Zaydun G, Tomiyama H, Hashimoto $\mathrm{H}$, et al. Menopause is an independent factor augmenting the age-related increase in arterial stiffness in the early postmenopausal phase. Atherosclerosis 2006;184(1):137-142

29 van Kesteren PJ, Kooistra T, Lansink M, et al. The effects of sex steroids on plasma levels of marker proteins of endothelial cell functioning. Thromb Haemost 1998;79(5):1029-1033

30 Romero JC, Reckelhoff JF. State-of-the-art lecture. Role of angiotensin and oxidative stress in essential hypertension. Hypertension 1999;344 Pt 2 :943-949

31 Reckelhoff JF, Romero JC. Role of oxidative stress in angiotensin-induced hypertension. Am J Physiol Regul Integr Comp Physiol 2003;284(4):R893-R912

32 Castelao JE, Gago-Dominguez M. Risk factors for cardiovascular disease in women: relationship to lipid peroxidation and oxidative stress. Med Hypotheses 2008;71(1):39-44 